Cite this: RSC Adv., 2018, 8, 12282
Check for updates

\section{Amine-functionalized MIL-53(Al) with embedded ruthenium nanoparticles as a highly efficient catalyst for the hydrolytic dehydrogenation of ammonia borane $\uparrow$}

\begin{abstract}
Shuren Zhang, (iD Liqun Zhou* and Menghuan Chen (D)
Well-dispersed ruthenium nanoparticles (Ru NPs) are immobilized within the pores of amine-functionalized MIL-53 via an in situ impregnation-reduction method. The resulting Ru/MIL-53(Al)- $\mathrm{NH}_{2}$ catalyst exhibits superior catalytic performance for the dehydrogenation of ammonia borane (AB) at ambient temperature relative to the $\mathrm{Ru} / \mathrm{MIL}-53(\mathrm{Al})$ catalyst; it has a turnover frequency (TOF) of $287 \mathrm{~mol} \mathrm{H}_{2} \mathrm{~min}^{-1}(\mathrm{~mol} \mathrm{Ru})^{-1}$ and an activation energy $\left(E_{\mathrm{a}}\right)$ of $30.5 \mathrm{~kJ} \mathrm{~mol}^{-1}$. The amine groups present in the MIL-53(Al)- $\mathrm{NH}_{2}$ framework facilitate the formation and stabilization of ultra-small Ru NPs by preventing their aggregation. Additionally, the Ru/MIL-53(Al)- $\mathrm{NH}_{2}$ catalyst exhibits satisfactory durability and reusability: $72.4 \%$ and $86.3 \%$ of the initial catalytic activity was maintained after the fifth successive cycle of the hydrolytic dehydrogenation of $A B$ in the two respective tests.
\end{abstract}

Received 18th February 2018

Accepted 26th March 2018

DOI: $10.1039 / \mathrm{c} 8 \mathrm{ra01507d}$

rsc.li/rsc-advances

internal pore surface is another important characteristic of MOFs. ${ }^{11}$ To date, a series of functionalized MOFs that incorporate a variety of functional groups (e.g., $-\mathrm{OH}$ and $-\mathrm{NH}_{2}$ ) has been successfully prepared. ${ }^{12,13}$ Among them, amine groups have attracted the most attention from researchers due to their ability to function as interaction sites for supported metallic nanoclusters in heterogeneous catalysis. ${ }^{\mathbf{1 4}}$ In addition, functionalization with aromatic $-\mathrm{NH}_{2}$ groups may facilitate metal complex binding, as demonstrated by $\mathrm{M}$. J. Ingleson et al. ${ }^{15}$ However, the utilization of these functionalized MOFs as catalysts in the dehydrogenation of $\mathrm{AB}$ aqueous solution has rarely been reported.

Recently, supported metal nanoparticles (NPs) have been extensively used in the hydrolysis of $\mathrm{AB}^{,{ }^{\mathbf{1 6}}}$ and increasing attempts have been devoted to encapsulating well-distributed and ultra-small metal NPs within MOF materials. In previous studies, researchers focused on immobilizing bimetallic or trimetallic alloy NPs in matrixes to improve the catalysis of $A B$ hydrolysis through the synergistic effects of metal NPs, such as CuNi/MIL-101, ${ }^{17}$ RuCo/MIL-96, ${ }^{18}$ RuCuCo/MIL-101, ${ }^{19}$ and $\mathrm{Ag}_{30} \mathrm{~Pb}_{70} / \mathrm{C} .{ }^{20}$ However, no studies have described the impact of amine-functionalized MOFs on AB hydrolysis. In this work, as a supporting material for metal loading, amine-functionalized MOFs may prove to be an effective strategy for the design and development of highly active hybrid materials for achieving high catalytic hydrogen generation from $\mathrm{AB}$ hydrolysis, and also offers a helpful overview of the exploration of stable and efficient MOF-based catalysts for solving various global environmental and energy problems.
Hubei Collaborative Innovation Center for Advanced Organic Chemical Materials, Ministry of Education Key Laboratory for the Synthesis and Application of Organic Functional Molecules, College of Chemistry and Chemical Engineering, Hubei University, Wuhan 430062, PR China.E-mail: zhoulq2003@163.com; zhangsr351@ 163.com; Fax: +8627 88663043; Tel: +86 2788662747

$\dagger$ Electronic supplementary information (ESI) available. See DOI: 10.1039/c8ra01507d 
In this work, we describe the preparation of Ru NPs embedded in MIL-53(Al)- $\mathrm{NH}_{2}$ through an in situ impregnation-reduction method. First, the uncoordinated amine groups of MIL-53(Al)- $\mathrm{NH}_{2}$ served as anchoring groups for capturing $\mathrm{Ru}(\mathrm{III})$ ions; these amine groups, which are located at the 2-amino-1,4-benzenedicarboxylic acid linkers in MIL-53(Al)- $\mathrm{NH}_{2}$, function as Lewis bases to stabilize $\mathrm{RuCl}_{3}$ during the impregnation process. The strong interaction between the electron lone pair of nitrogen and the d-orbital of the $\mathrm{Ru}$ atoms ensure that the formation of Ru NPs is confined to the pores of MIL-53(Al)$\mathrm{NH}_{2}$ during the reduction process, thereby resulting in the successful embedding of ultra-small Ru NPs in the MIL-53(Al)- $\mathrm{NH}_{2}$. Thus, a catalyst of MIL-53(Al)- $\mathrm{NH}_{2}$ containing embedded $\mathrm{Ru}$ NPs was successfully synthesized. PXRD, FT-IR, BET, TEM, EDX, XPS, and ICPAES measurements were performed to assess the structure, size, morphology, and composition of the $\mathrm{Ru} / \mathrm{MIL}-53(\mathrm{Al})-\mathrm{NH}_{2}$ catalyst. To compare the turnover frequency (TOF) and activation energy $\left(E_{\mathrm{a}}\right)$ values of the $\mathrm{Ru} / \mathrm{MIL}-53(\mathrm{Al})-\mathrm{NH}_{2}$ catalyst with those of the $\mathrm{Ru} / \mathrm{MIL}$ 53(Al) catalyst in $\mathrm{AB}$ hydrolysis, relevant experiments were performed under the same conditions with both catalysts. To provide more insight into the reduction in catalytic activity, durability and reusability tests were performed with both catalysts. To the best of our knowledge, there are no reports of the hydrolysis of $\mathrm{AB}$ at room temperature using metal NPs immobilized in an aminefunctionalized-MOF with a non-functionalized-MOF for comparison.

\section{Experimental}

\section{Synthesis of MIL-53(Al)-NH $\mathrm{NH}_{2}$ and MIL-53(Al)}

The preparation of MIL-53(Al)- $\mathrm{NH}_{2}$ was accomplished using a reported method. ${ }^{21}$ 2-Amino-1,4-benzenedicarboxylic acid $\left(\mathrm{NH}_{2}-\mathrm{BDC}\right)$ and aluminum nitrate nonahydrate $\left(\mathrm{Al}\left(\mathrm{NO}_{3}\right) \cdot 9 \mathrm{H}_{2} \mathrm{O}\right)$ were used as the organic linker and the metal source, respectively. Typically, $750.3 \mathrm{mg}$ of $\mathrm{Al}\left(\mathrm{NO}_{3}\right) \cdot 9 \mathrm{H}_{2} \mathrm{O}$ and $362.3 \mathrm{mg}$ of $\mathrm{NH}_{2}$-BDC were mixed with pure deionized water, and the total volume of solvent was maintained at $5 \mathrm{~mL}$. The reactants were transferred to a $50 \mathrm{~mL}$ Teflon-lined stainless steel autoclave and heated at $150{ }^{\circ} \mathrm{C}$ for 5 hours. After natural cooling, the resulting yellow products were refluxed in $25 \mathrm{~mL}$ of $\mathrm{N}, \mathrm{N}$-dimethylformamide (DMF) at $150{ }^{\circ} \mathrm{C}$ for 8 hours to remove residual water or unreacted 2-amino-1,4-benzenedicarboxylic acid molecules trapped in the frameworks of MIL-53(Al)- $\mathrm{NH}_{2}$. After filtering and washing with acetone and ethanol, the resulting yellow products were dried overnight in a vacuum drying oven at $60{ }^{\circ} \mathrm{C}$. MIL-53(Al) was also hydrothermally synthesized according to the reported approach. ${ }^{22}$ Typically, the molar ratio of 1,4-benzenedicarboxylic acid, aluminum nitrate nonahydrate, and deionized water was fixed at $0.5: 1: 80$. The reactants were placed in a $50 \mathrm{~mL}$ Teflon-lined stainless steel autoclave and heated at $210{ }^{\circ} \mathrm{C}$ for 72 hours. After natural cooling in the autoclave, the resulting white products were obtained by filtration, washed with deionized water, and dried in a vacuum drying oven at $60^{\circ} \mathrm{C}$.

\section{Synthesis of Ru/MIL-53(Al)-NH $\mathrm{NH}_{2}$ and $\mathrm{Ru} / \mathrm{MIL}-53(\mathrm{Al})$ catalysts}

In the typical synthesis of the $\mathrm{Ru} / \mathrm{MIL}-53(\mathrm{Al})-\mathrm{NH}_{2}$ catalyst, $50.0 \mathrm{mg}$ of $\mathrm{MIL}-53(\mathrm{Al})-\mathrm{NH}_{2}$ was dispersed in a mixture composed of $10 \mathrm{~mL}$ deionized water and $10 \mathrm{~mL}$ ethanol in a flask via ultrasonication for 10 minutes to obtain a highly dispersed MIL-53(Al)- $\mathrm{NH}_{2}$ suspension. Next, 4, 6, 8, 10 or $12 \mathrm{~mL}$ of the solution containing $0.01 \mathrm{M}$ ruthenium(III) chloride $\left(\mathrm{RuCl}_{3}\right)$ was added to the flask, which was then ultrasonicated for 10 minutes to obtain a uniform dispersion. Magnetic stirring was performed for 5 hours to impregnate the metal salts. Subsequently, $37.8 \mathrm{mg}$ of sodium tetrahydroborate $\left(\mathrm{NaBH}_{4}\right.$, $1 \mathrm{mM}$ ) dissolved in $10 \mathrm{~mL}$ deionized water was added dropwise into the uniform dispersion to reduce the Ru(III) ions. After 4 hours of stirring, the resulting solid was obtained through filtration, washed with ethanol and deionized water, and dried overnight in a vacuum drying oven at $60{ }^{\circ} \mathrm{C}$. The Ru/MIL-53(Al) catalyst was synthesized by the same process. For comparison of the catalytic activities, Ru nanoparticles (NPs) without the MIL53(Al)- $\mathrm{NH}_{2}$ or MIL-53(Al) support were also synthesized through an identical route, and the addition level of $\mathrm{Ru}(10 \mathrm{~mL}, 0.01 \mathrm{M}$ $\left.\mathrm{RuCl}_{3}\right)$ was matched to that in the $\mathrm{Ru} / \mathrm{MIL}-53(\mathrm{Al})-\mathrm{NH}_{2}(\mathrm{Al})$ catalyst.

\section{Catalytic performance}

To assess the catalytic activities of the $\mathrm{Ru} / \mathrm{MIL}-53(\mathrm{Al})-\mathrm{NH}_{2}$ and $\mathrm{Ru}$ / MIL-53(Al) catalysts in the dehydrogenation of ammonia borane (AB) aqueous solution, a hydrogen evolution experiment was performed in a two-necked round bottom flask containing $5 \mathrm{mg}$ of the $\mathrm{Ru} / \mathrm{MIL}-53(\mathrm{Al})-\mathrm{NH}_{2}$ or $\mathrm{Ru} / \mathrm{MIL}-53(\mathrm{Al})$ catalyst dispersed in $10 \mathrm{~mL}$ of deionized water. One neck was connected to a graduated cylinder used to monitor the volume of gas evolved, and the other neck was connected to a pressure-equalization funnel used to introduce $4 \mathrm{~mL}$ of the $\mathrm{AB}(18.5 \mathrm{mg})$ aqueous solution. The hydrolysis of $\mathrm{AB}$ was rapidly initiated upon the addition of the aqueous $\mathrm{NH}_{3} \mathrm{BH}_{3}$ solution to the catalysts, and the displacement of water in the cylinder, which is identical to the volume of generated hydrogen gas, was recorded at constant intervals (15 s). A water bath was employed to maintain reaction temperature at $25{ }^{\circ} \mathrm{C}$. To determine the $E_{\mathrm{a}}$, the hydrolytic experiments were conducted at various temperatures $\left(25,30,35\right.$, and $\left.40{ }^{\circ} \mathrm{C}\right)$ using the $\mathrm{Ru} / \mathrm{MIL}-53(\mathrm{Al})-\mathrm{NH}_{2}$ or $\mathrm{Ru} / \mathrm{MIL}-53(\mathrm{Al})$ catalyst under ambient atmosphere.

To determine the most active $\mathrm{Ru}$ loading for $\mathrm{Ru} / \mathrm{MIL}-53(\mathrm{Al})-\mathrm{NH}_{2}$ in the hydrolysis of $\mathrm{AB}$, a set of experiments with various initial addition levels of $\mathrm{Ru} / \mathrm{MIL}-53(\mathrm{Al})-\mathrm{NH}_{2}(n(\mathrm{Ru})=0.04,0.06,0.08,0.10$, $0.12 \mathrm{mmol})$ were performed at room temperature $\left(25^{\circ} \mathrm{C}\right)$ while maintaining the same amount of $\mathrm{AB}(18.5 \mathrm{mg})$, and hydrogen generation was measured. The highest catalytic activity was obtained with the addition of $0.10 \mathrm{mmol} \mathrm{Ru}$ in the $\mathrm{Ru} / \mathrm{MIL}-53(\mathrm{Al})-$ $\mathrm{NH}_{2}$ catalyst. For all the experiments reported hereinafter, the $\mathrm{Ru}$ / MIL-53(Al)- $\mathrm{NH}_{2}$ catalyst using $0.10 \mathrm{mmol} \mathrm{Ru}$ was tested unless otherwise stated.

\section{Durability and reusability tests of $\mathrm{Ru} / \mathrm{MIL}-53(\mathrm{Al})-\mathrm{NH}_{2}$ and $\mathrm{Ru}$ / MIL-53(Al) catalysts}

For the durability test, the catalytic reaction was repeated 5 times by introducing another equivalent of $\mathrm{AB}(18.5 \mathrm{mg})$ into the solution after completion of the previous cycle. For the reusability test, $10 \mathrm{mg}$ of catalyst was employed in the hydrolytic 
reaction of $\mathrm{AB}$. The catalysts were collected after each reaction by centrifugation and washed with deionized water three times. Supernatant liquid was decanted, and the isolated catalysts were redispersed in $10 \mathrm{~mL}$ deionized water via ultrasonication for 10 minutes. Subsequently, a fresh $4 \mathrm{~mL}$ of the $\mathrm{AB}(18.5 \mathrm{mg})$ aqueous solution was introduced into the reactor containing catalysts redispersed in $10 \mathrm{~mL}$ deionized water. The volume of generated hydrogen gas was recorded again.

\section{Characterization}

Powder X-ray diffraction (PXRD) patterns were collected on a Bruker D8-Advance diffractometer (Bruker AXS, Germany) equipped with a $\mathrm{Cu} \mathrm{K} \alpha$ radiation source $(\lambda=1.5418 \AA)$ with scanning rate at $1^{\circ} \mathrm{min}^{-1}$ in the $2 \theta$ range of $5-65^{\circ}$. Fourier transform infrared (FT-IR) spectra were collected on an Impact 420 Nicolet instrument (Madison, WI, USA) to determine the structures of the MIL-53(Al)- $\mathrm{NH}_{2}$ and $\mathrm{Ru} / \mathrm{MIL}-53(\mathrm{Al})-\mathrm{NH}_{2}$ catalysts. Brunauer-Emmett-Teller (BET) specific surface area measurements were performed on $\mathrm{N}_{2}$ sorption isotherms obtained at $77 \mathrm{~K}$ using a 2SI-MP-9 instrument (Quantachrome Instruments, America). The morphologies and compositions of the samples were observed using a JEM-2100F (JEOL, Japan) transmission electron microscope (TEM) equipped with an energy dispersive X-ray (EDX) detector at an acceleration voltage of $200 \mathrm{kV}$. X-ray photoelectron spectroscopy (XPS) was employed to investigate the electronic states of the obtained $\mathrm{Ru} / \mathrm{MIL}$ 53(Al)- $\mathrm{NH}_{2}$ using ESCALAB 250XI (Thermo Fisher Scientific, America). The actual metal content of the prepared catalysts and the metal leaching of the $\mathrm{Ru} / \mathrm{MIL}-53(\mathrm{Al})-\mathrm{NH}_{2}$ catalyst in the five consecutive cycles were measured with an IRIS intrepid II XSP (Thermo Fisher Scientific, America) inductively coupled plasma atomic emission spectroscope (ICP-AES).

\section{Results and discussion}

Samples of MIL-53(Al)- $\mathrm{NH}_{2}, \mathrm{Ru} / \mathrm{MIL}-53(\mathrm{Al})-\mathrm{NH}_{2}, \mathrm{MIL}-53(\mathrm{Al})$, and $\mathrm{Ru} / \mathrm{MIL}-53(\mathrm{Al})$ were characterized by powder X-ray diffraction (PXRD). As shown in Fig. 1a, the PXRD patterns of MIL53(Al)- $\mathrm{NH}_{2}$ and MIL-53(Al) agree with the published PXRD results, ${ }^{21,22}$ which demonstrates the formation of MIL-53(Al)$\mathrm{NH}_{2}$ and MIL-53(Al). Additionally, the diffraction peaks of $\mathrm{Ru}$ / MIL-53(Al)- $\mathrm{NH}_{2}(\mathrm{Al})$ and $\mathrm{Ru} / \mathrm{MIL}-53(\mathrm{Al})$ samples match well with those of MIL-53(Al)-NH $\mathrm{NH}_{2}$ and MIL-53(Al), respectively, suggesting that the integrities of the matrix frameworks remained unchanged despite the introduction of a high Ru NP loading. However, the intensities of the peaks decreased substantially as a result of loading $\mathrm{Ru}$ NPs into the MOF frameworks. ${ }^{11}$ Furthermore, in the magnified PXRD patterns (Fig. 1b) of the $\mathrm{Ru} / \mathrm{MIL}-53(\mathrm{Al})-\mathrm{NH}_{2}$ and $\mathrm{Ru} / \mathrm{MIL}-53(\mathrm{Al})$ catalysts, a peak is found at $2 \theta=42.1^{\circ}$, which indicates the presence of $\mathrm{Ru}$ in the $\mathrm{Ru} / \mathrm{MIL}$ 53(Al)- $\mathrm{NH}_{2}$ and $\mathrm{Ru} / \mathrm{MIL}-53(\mathrm{Al})$ catalysts.

The FT-IR spectra of MIL-53(Al)- $\mathrm{NH}_{2}, \mathrm{Ru} / \mathrm{MIL}-53(\mathrm{Al})-\mathrm{NH}_{2}$, and $\mathrm{Ru} / \mathrm{MIL}-53(\mathrm{Al})-\mathrm{NH}_{2}$ after the fifth cycle of durability testing are shown in Fig. 2. The two peaks located at 3498.7 and $3382.4 \mathrm{~cm}^{-1}$ in MIL-53(Al)- $\mathrm{NH}_{2}$, at 3497.1 and $3388.1 \mathrm{~cm}^{-1}$ in $\mathrm{Ru} / \mathrm{MIL}-53(\mathrm{Al})-\mathrm{NH}_{2}$, and at 3496.9 and $3388.0 \mathrm{~cm}^{-1}$ in $\mathrm{Ru} / \mathrm{MIL}-$
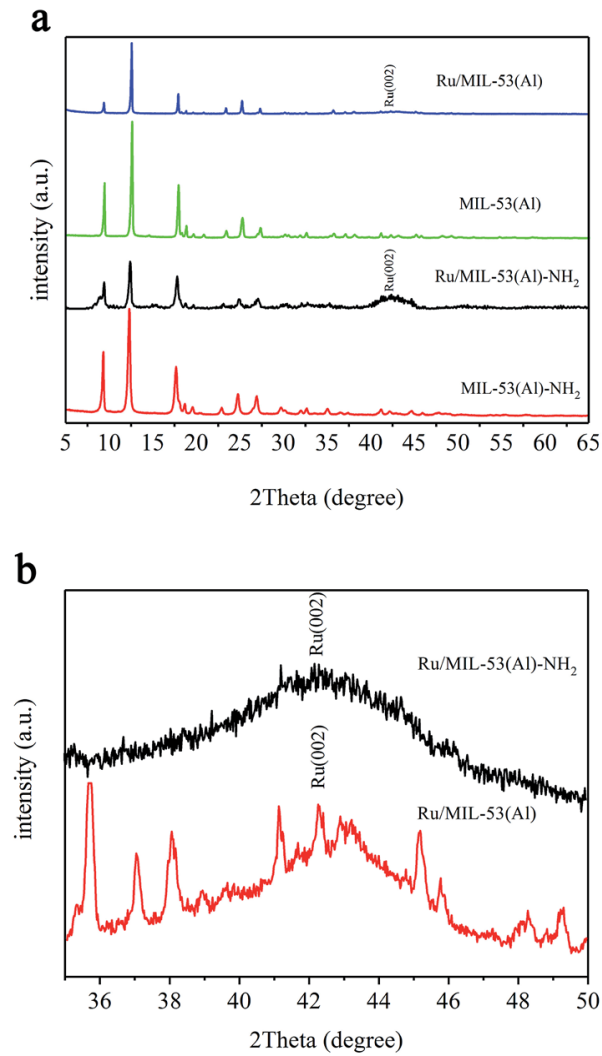

Fig. 1 (a) Wide-angle and (b) magnified Ru PXRD patterns of Ru/MIL53(Al), MIL-53(Al), Ru/MIL-53(Al)- $\mathrm{NH}_{2}$, and MIL-53(Al)- $\mathrm{NH}_{2}$.

53(Al) $-\mathrm{NH}_{2}$ after durability testing are assigned to the amine groups in the three samples, and the peaks at 1584.3, 1581.1, and $1580.0 \mathrm{~cm}^{-1}$ originate from $\delta_{\mathrm{NH}}$. In addition, the $\nu_{\mathrm{C}=\mathrm{O}}$ of DMF $\left(1670.2 \mathrm{~cm}^{-1}\right)$ is observed in the spectrum of MIL-53(Al)$\mathrm{NH}_{2},{ }^{21}$ because the DMF molecules trapped in the pores of MIL53(Al)- $\mathrm{NH}_{2}$ were not completely removed during washing. However, during the preparation of the $\mathrm{Ru} / \mathrm{MIL}-53(\mathrm{Al})-\mathrm{NH}_{2}$ catalyst, when the salts containing $\mathrm{Ru}(\mathrm{III})$ ions and $\mathrm{NaBH}_{4}$ were added, a reduction reaction occurred, and the DMF molecules were replaced by the resulting Ru NPs. Consequently, the $\nu_{\mathrm{C}=\mathrm{O}}$ from the DMF molecules vanished after the Ru NP loading

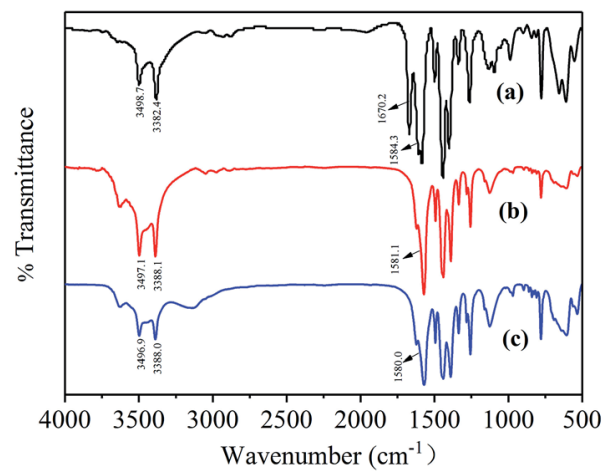

Fig. 2 FT-IR spectra of (a) MIL-53(Al)- $\mathrm{NH}_{2}$, (b) Ru/MIL-53(Al)- $\mathrm{NH}_{2}$, and (c) Ru/MIL-53(Al)- $\mathrm{NH}_{2}$ after the fifth run in the durability test. 
process. Compared with the $\mathrm{Ru} / \mathrm{MIL}-53(\mathrm{Al})-\mathrm{NH}_{2}$, the positions of the main bands of $\mathrm{Ru} / \mathrm{MIL}-53(\mathrm{Al})-\mathrm{NH}_{2}$ after the fifth run in durability testing show no obvious changes, indicating that the main structure of the $\mathrm{Ru} / \mathrm{MIL}-53(\mathrm{Al})-\mathrm{NH}_{2}$ remained unchanged.

The $\mathrm{N}_{2}$ sorption isotherms of the MIL-53(Al)- $\mathrm{NH}_{2}$ and $\mathrm{Ru} /$ MIL-53(Al)- $\mathrm{NH}_{2}$ samples are shown in Fig. S1a and b. $\dagger$ The Brunauer-Emmett-Teller (BET) specific surface area of MIL$53(\mathrm{Al})-\mathrm{NH}_{2}$ is $162.4 \mathrm{~m}^{2} \mathrm{~g}^{-1}$, which is approximately the same as previously reported values. ${ }^{23}$ Additionally, the pore volume and pore size of MIL-53(Al)- $\mathrm{NH}_{2}$ were measured at $0.8407 \mathrm{~cm}^{3} \mathrm{~g}^{-1}$ and $2.07 \mathrm{~nm}$, respectively (Fig. S1c $\dagger$ ). However, the surface area of MIL-53(Al)- $\mathrm{NH}_{2}$ decreased significantly to $57.7 \mathrm{~m}^{2} \mathrm{~g}^{-1}$ after the immobilization of $\mathrm{Ru}$ NPs. Accordingly, the pore size decreased from 2.07 to $1.08 \mathrm{~nm}$ (Fig. S1d $\dagger$ ), and the corresponding pore volume of MIL-53(Al)- $\mathrm{NH}_{2}$ also decreased from 0.8407 to $0.1557 \mathrm{~cm}^{3} \mathrm{~g}^{-1}$. These results indicate that the cavities of MIL-53(Al)- $\mathrm{NH}_{2}$ are either obstructed or occupied by the relatively small $\mathrm{Ru} \mathrm{NPs}$, directly decreasing the specific area, pore size, and pore volume.

The morphology and particle size of the Ru/MIL-53(Al)- $\mathrm{NH}_{2}$ catalyst before and after five consecutive cycles were further investigated by transmission electron microscopy (TEM). The TEM images of the initially obtained $\mathrm{Ru} / \mathrm{MIL}-53(\mathrm{Al})-\mathrm{NH}_{2}$ catalysts (Fig. 3a and b) and those after a fifth run (Fig. 3c and d) clearly show the presence of many ultra-small particles in the matrix, and these NPs are well distributed without agglomeration. As shown in Fig. 3e, the diameters of the Ru NPs in the Ru/ MIL-53(Al)- $\mathrm{NH}_{2}$ catalyst have a very narrow size distribution ranging from $0.3 \mathrm{~nm}$ to $2.4 \mathrm{~nm}$, and the mean diameter is only $1.22 \pm 0.34 \mathrm{~nm}$, which indicates that a large proportion of the $\mathrm{Ru}$ NPs are smaller than the mean diameter of the MIL-53(Al)$\mathrm{NH}_{2}$ pores $(2.07 \mathrm{~nm})$. Therefore, Ru NPs were successfully embedded in the frameworks of MIL-53(Al)- $\mathrm{NH}_{2}$, and other larger Ru NPs were supported on the surface. These ultra-small $\mathrm{Ru}$ NPs embedded in the MIL-53(Al)- $\mathrm{NH}_{2}$ greatly enhanced the performance of the $\mathrm{Ru} / \mathrm{MIL}-53(\mathrm{Al})-\mathrm{NH}_{2}$ catalyst.

As shown in Fig. 3c and d, after five catalytic cycles, no obvious changes in the morphology of the Ru/MIL-53(Al)- $\mathrm{NH}_{2}$ catalyst or the uniform distribution of the $\mathrm{Ru}$ NPs were observed, and Fig. 3f shows the corresponding particle size distribution of the catalyst after five cycles with a mean diameter of $1.60 \pm 0.33 \mathrm{~nm}$. These results confirmed that the crystalline structure of MIL-53(Al)- $\mathrm{NH}_{2}$ remained nearly unchanged after the fifth cycle and that the ultra-small $\mathrm{Ru}$ NPs remained immobilized in the frameworks of MIL-53(Al)- $\mathrm{NH}_{2}$. The EDX spectrum shown in Fig. $3 \mathrm{~g}$ further confirms the presence of $\mathrm{Ru}$ in the $\mathrm{Ru} / \mathrm{MIL}-53(\mathrm{Al})-\mathrm{NH}_{2}$ catalyst. Notably, the peaks at approximately 8 and $9 \mathrm{keV}$ can be attributed to the copper grid.

To investigate the chemical states of the $\mathrm{Ru} / \mathrm{MIL}-53(\mathrm{Al})-\mathrm{NH}_{2}$ catalyst, X-ray photoelectron spectroscopy (XPS) was performed. Fig. 4a displays the survey XPS spectrum of the prepared $\mathrm{Ru}$ / MIL-53(Al)- $\mathrm{NH}_{2}$ catalyst; the main absorption peaks are assigned to $\mathrm{C} 1 \mathrm{~s}, \mathrm{Ru} 3 \mathrm{~d}, \mathrm{Ru} 3 \mathrm{p}$, and $\mathrm{O} 1 \mathrm{~s}$. Notably, there is some overlap between the $\operatorname{Ru}(0) 3 d$ peak and the $C 1$ s peak at approximately $284.7 \mathrm{eV},{ }^{24}$ which can make it difficult to adequately analyze the appropriate region of $\mathrm{Ru}$. Fig. $4 \mathrm{~b}$ shows that the signals of $\mathrm{Ru} 3 \mathrm{p}$ present two adsorption peaks located at $462.0 \mathrm{eV}$ and $485.1 \mathrm{eV}$, which are assigned to $\mathrm{Ru} 3 \mathrm{p}_{3 / 2}$ and $3 \mathrm{p}_{1 /}$ ${ }_{2}$, respectively ${ }^{25}$ These results reveal that $\mathrm{Ru}$ is stable in the $\mathrm{Ru}$ / MIL-53(Al)- $\mathrm{NH}_{2}$ catalyst. The amine groups of MIL-53(Al)- $\mathrm{NH}_{2}$ acted as anchoring groups, and the $\mathrm{Ru}(\mathrm{III})$ ions were then reduced to $\mathrm{Ru}(0)$ by the $\mathrm{NaBH}_{4}$ reducing agent.

The catalytic performance of $\mathrm{Ru} / \mathrm{MIL}-53(\mathrm{Al})-\mathrm{NH}_{2}$ with various ICP-AES-authenticated Ru loadings of 11.33, 13.68, 16.69, 18.10,

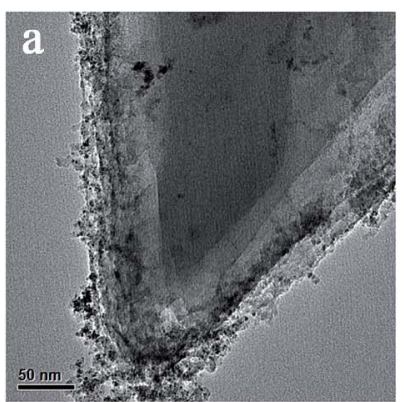

e

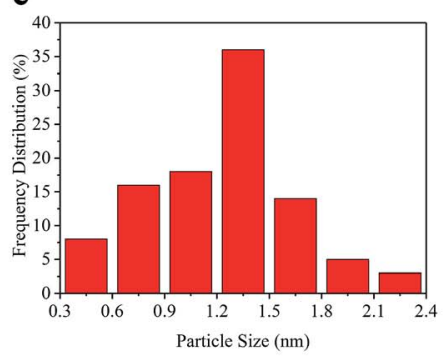

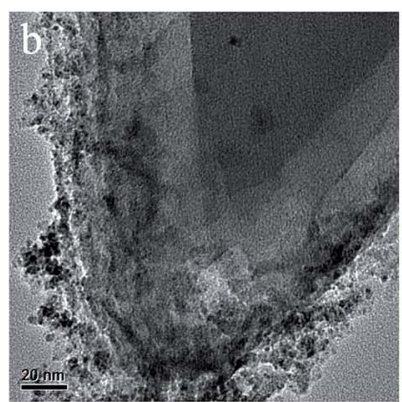

f

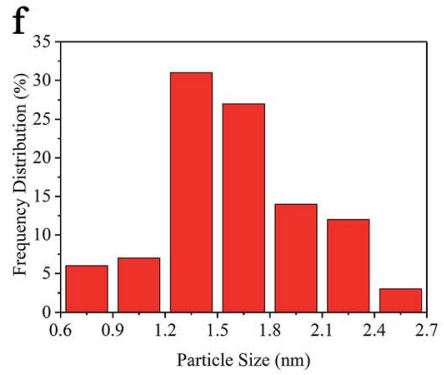

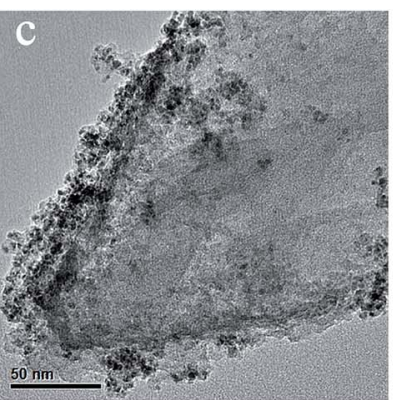
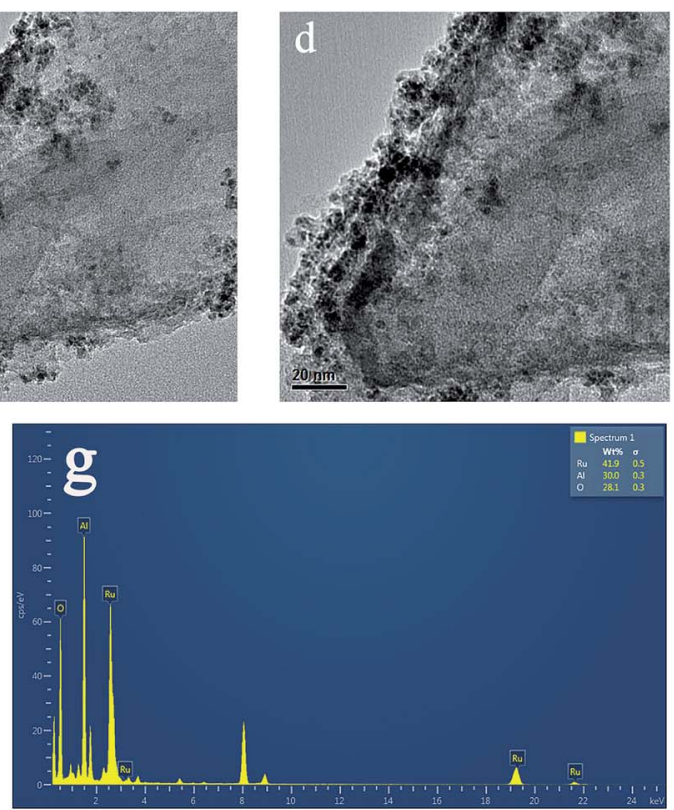

Fig. 3 TEM images of (a and b) initially prepared Ru/MIL-53(Al)- $\mathrm{NH}_{2}$ and (c and d) Ru/MIL-53(Al)- $\mathrm{NH}_{2}$ after five catalytic cycles; particle size distribution of (e) initially prepared Ru/MIL-53(Al)- $\mathrm{NH}_{2}$ and (f) $\mathrm{Ru} / \mathrm{MIL}-53(\mathrm{Al})-\mathrm{NH}_{2}$ after five catalytic cycles; (g) EDX spectrum of Ru/MIL-53(Al)$\mathrm{NH}_{2}$. 
and 19.42 wt $\%$ was compared, and TOF values for these preparations were measured. As shown in Fig. $\mathrm{S} 2$ and $\mathrm{S} 3, \dagger$ the $\mathrm{Ru} /$ MIL-53(Al)- $\mathrm{NH}_{2}$ sample with initial $\mathrm{Ru}$ addition level of $0.10 \mathrm{mmol}$ displays the highest catalytic activity for the hydrolysis of $\mathrm{AB}$ at $25{ }^{\circ} \mathrm{C}$. It is worth noting that the TOF values first increase and then decrease as the initial $\mathrm{Ru}$ addition level increases, revealing a volcano-shaped trend (Fig. S3†). This phenomenon can be attributed to the agglomeration of nanoparticles, which leads to a decrease in the accessibility of active sites. $^{26}$

The ICP-AES was also performed on the Ru/MIL-53(Al)- $\mathrm{NH}_{2}$ and $\mathrm{Ru} / \mathrm{MIL}-53(\mathrm{Al})$ catalysts to determine their authentic $\mathrm{Ru}$ loadings. The results showed that the actual content of $\mathrm{Ru}$ in the $\mathrm{Ru} / \mathrm{MIL}-53(\mathrm{Al})-\mathrm{NH}_{2}$ and $\mathrm{Ru} / \mathrm{MIL}-53(\mathrm{Al})$ catalysts was 18.10 and $12.85 \mathrm{wt} \%$, respectively, although the amount of $\mathrm{RuCl}_{3}$ added to the reaction solution was $0.10 \mathrm{mmol}$ in both cases. Thus, the actual $\mathrm{Ru}$ loading in the $\mathrm{Ru} / \mathrm{MIL}-53(\mathrm{Al})-\mathrm{NH}_{2}$ catalyst far exceeds that in the $\mathrm{Ru} / \mathrm{MIL}-53(\mathrm{Al})$ catalyst. A plausible explanation is that the majority of $\mathrm{Ru}(\mathrm{III})$ ions were adsorbed by the amine groups in the MIL-53(Al)- $\mathrm{NH}_{2}$ framework. The higher $\mathrm{Ru}$ loading catalytic performance for the $\mathrm{Ru} / \mathrm{MIL}-53(\mathrm{Al})-\mathrm{NH}_{2}$ catalyst compared with the $\mathrm{Ru} / \mathrm{MIL}-53(\mathrm{Al})$ catalyst.

The catalytic activities of the prepared $\mathrm{Ru} / \mathrm{MIL}-53(\mathrm{Al})-\mathrm{NH}_{2}$ and $\mathrm{Ru} / \mathrm{MIL}-53(\mathrm{Al})$ catalysts in the hydrolysis of $\mathrm{AB}$ were systematically evaluated at $25{ }^{\circ} \mathrm{C}$. To compare the catalytic performances, the same amount of Ru NPs was synthesized through reduction by $\mathrm{NaBH}_{4}$ without the MIL-53(Al)- $\mathrm{NH}_{2}$ or MIL-53(Al) support and utilized in the hydrolysis of AB. As
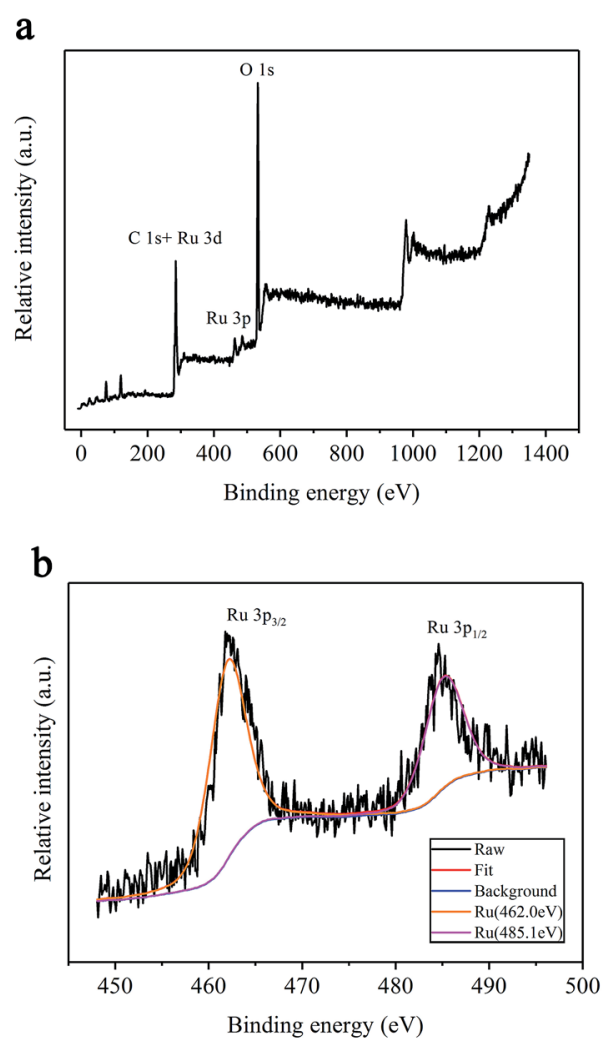

Fig. 4 XPS spectra of the synthesized Ru/MIL-53(Al)- $\mathrm{NH}_{2}$ catalyst: (a) survey scan and (b) Ru 3p spectrum. shown in Fig. 5, MIL-53(Al)- $\mathrm{NH}_{2}$ and MIL-53(Al) exhibited no catalytic activity toward the dehydrogenation of $\mathrm{AB}$ aqueous solution, whereas the reaction time for the complete hydrogen release $\left(\mathrm{mol} \mathrm{H}_{2} / \mathrm{mol} \mathrm{AB}=3.0\right)$ was more than 10 minutes for the same amount of Ru NPs lacking the matrix. Additionally, the $\mathrm{Ru} / \mathrm{MIL}-53(\mathrm{Al})-\mathrm{NH}_{2}$ catalyst displayed superior catalytic activity compared with the $\mathrm{Ru} / \mathrm{MIL}-53(\mathrm{Al})$ and $\mathrm{Ru}$ NPs catalysts: the $\mathrm{Ru}$ / MIL-53(Al)- $\mathrm{NH}_{2}$ catalyst with a $\mathrm{Ru}$ content of $18.10 \mathrm{wt} \%$ exhibited the highest TOF value of $287 \mathrm{~mol} \mathrm{H}_{2} \min ^{-1}$ (mol $\mathrm{Ru})^{-1}$. In contrast, a TOF value of $218 \mathrm{~mol} \mathrm{H}_{2} \min ^{-1}(\mathrm{~mol} \mathrm{Ru})^{-1}$ was calculated for the Ru/MIL-53(Al) catalyst, which generally agrees with previously reported values. ${ }^{27}$ Therefore, the TOF value of the $\mathrm{Ru} / \mathrm{MIL}-53(\mathrm{Al})-\mathrm{NH}_{2}$ catalyst is much larger than that of the Ru/MIL-53(Al) in this study. Moreover, this value is higher than those of most Ru-based catalysts, which are illustrated in Table 1. These experimental results reveal that the bifunctional effects of the $\mathrm{Ru}$ NPs and the MIL-53(Al)- $\mathrm{NH}_{2}$ framework dramatically increased the catalytic activity of the $\mathrm{Ru} / \mathrm{MIL}$ $53(\mathrm{Al})-\mathrm{NH}_{2}$ catalyst; MIL-53(Al)- $\mathrm{NH}_{2}$ offers an excellent framework for $\mathrm{Ru}$ NPs even though it does not participate in the $\mathrm{AB}$ hydrolysis. Additionally, the ultra-small size of the Ru NPs and the higher authentic $\mathrm{Ru}$ loading in the Ru/MIL-53(Al)- $\mathrm{NH}_{2}$ catalyst, both of which result from the presence of amine groups in the framework of MIL-53(Al)- $\mathrm{NH}_{2}$, contribute to this excellent catalytic performance. More importantly, these results also show that MIL-53(Al)- $\mathrm{NH}_{2}$ is superior to MIL-53(Al) as a matrix for the Ru NPs.

The catalytic reaction appears to occur on the exterior of the metal catalyst. ${ }^{37}$ A plausible two-step catalytic mechanism for the hydrolytic reaction is proposed as follows. First, AB interacts with the exterior of the $\mathrm{Ru}$ nanoparticles to form a transient activated $\mathrm{Ru}-\mathrm{H}$ species, which is accepted to be a precondition for the hydrolytic reaction. Then, $\mathrm{H}_{2}$ is generated after the attack of $\mathrm{H}_{2} \mathrm{O}$ molecules on the $\mathrm{Ru}-\mathrm{H}$ species. ${ }^{38}$ Because the amine groups could be used as anchoring groups to stabilize the Ru NPs, ultra-small and well-distributed NPs could be supported on the surface of the framework, which leads to a significant enhancement of surface contact among the Ru NPs and $\mathrm{AB}$ and an increase in the number of active sites that could form the activated transient $\mathrm{Ru}-\mathrm{H}$ species. Consequently, a higher hydrogen generation rate and productivity were noted

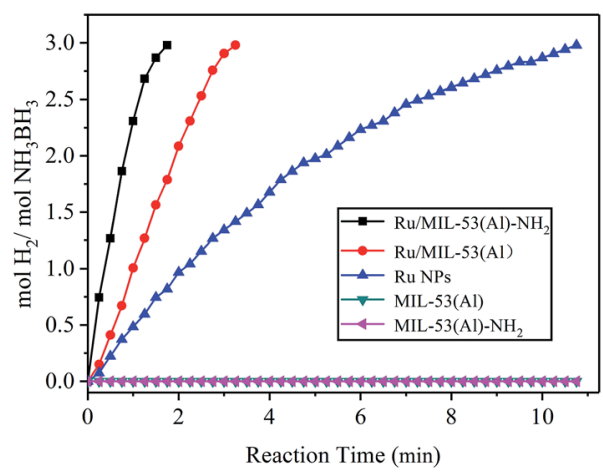

Fig. 5 Hydrogen generation from the hydrolysis of $A B$ catalyzed by $\mathrm{Ru} / \mathrm{MIL}-53(\mathrm{Al})-\mathrm{NH}_{2}, \mathrm{Ru} / \mathrm{MIL}-53$, Ru NPs, MIL-53(Al), and MIL-53(Al)$\mathrm{NH}_{2}$. 
Table 1 Catalytic activities of different Ru-based catalysts used for the hydrolytic dehydrogenation of $A B$

\begin{tabular}{|c|c|c|c|c|c|}
\hline Catalyst & 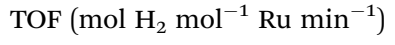 & $E_{\mathrm{a}}\left(\mathrm{kJ} \mathrm{mol}^{-1}\right)$ & $\ln A$ & Temperature range $\left({ }^{\circ} \mathrm{C}\right)$ & Ref. \\
\hline Ru@Ni & 339.5 & 36.59 & 26.55 & $25-40$ & 28 \\
\hline RuCuNi/CNTs & 311.15 & 36.67 & 34.27 & $25-40$ & 29 \\
\hline $\mathrm{Ru} / \mathrm{MIL}-53(\mathrm{Al})$ & 218 & 37.2 & 13.4 & $25-40$ & This study \\
\hline RuCuCo@MIL-101 & 241.2 & 48 & 36.91 & $25-40$ & 19 \\
\hline $\mathrm{Ru} / \mathrm{ND}$ & 229 & 50.7 & - & $20-35$ & 30 \\
\hline $\mathrm{Ru}^{0} / \mathrm{HfO}_{2}$ & 170 & 65 & - & $25-40$ & 33 \\
\hline Ru(0)@X-NW & 135 & 77 & 30.24 & $20-40$ & 34 \\
\hline CuRu@C-1b & 97 & 39.2 & - & $20-50$ & 35 \\
\hline $\mathrm{Ru} @ \mathrm{Al}_{2} \mathrm{O}_{3}$ & 83.3 & 48 & 23.6 & $25-40$ & 36 \\
\hline
\end{tabular}

for the $\mathrm{Ru} / \mathrm{MIL}-53(\mathrm{Al})-\mathrm{NH}_{2}$ catalyst relative to the $\mathrm{Ru} / \mathrm{MIL}-53(\mathrm{Al})$ catalyst.

To determine the $E_{\mathrm{a}}$ of the $\mathrm{AB}$ hydrolytic reaction catalyzed by the $\mathrm{Ru} / \mathrm{MIL}-53(\mathrm{Al})-\mathrm{NH}_{2}$ catalyst, the hydrolytic reactions were performed at various temperatures ranging from $25^{\circ} \mathrm{C}$ to $40^{\circ} \mathrm{C}$. The apparent $E_{\mathrm{a}}$ values for the hydrolysis of $\mathrm{AB}$ over the Ru/MIL53(Al)- $\mathrm{NH}_{2}$ and $\mathrm{Ru} / \mathrm{MIL}-53(\mathrm{Al})$ catalysts were determined from the Arrhenius equation (1), in which $k$ stands for the rate constant, and $A$ and $R$ represent the pre-exponential factor and gas constant, respectively. Fig. $6 \mathrm{a}$ and $\mathrm{c}$ indicate that the hydrolytic rates for both the Ru/MIL-53(Al)- $\mathrm{NH}_{2}$ and Ru/MIL53(Al) catalysts increased with increasing temperature, and the values of the rate constant $k$ for the hydrolytic reaction of $\mathrm{AB}$ were determined based on the slopes of the fitted lines and then were used to measure $E_{\mathrm{a}}$. The Arrhenius plot of $\ln k v s .1 / T$ for the $\mathrm{Ru} / \mathrm{MIL}-53(\mathrm{Al})-\mathrm{NH}_{2}$ catalyst is plotted in Fig. $6 \mathrm{~b}$, and the $E_{\mathrm{a}}$ for the hydrolytic reaction of $\mathrm{AB}$ was calculated as approximately $30.5 \mathrm{~kJ} \mathrm{~mol}^{-1}$. Fig. 6d shows an $E_{\mathrm{a}}$ for Ru/MIL-53(Al) of $37.2 \mathrm{~kJ} \mathrm{~mol}^{-1}$, which is approximately the same as previously reported values. ${ }^{27}$ Thus, the $E_{\mathrm{a}}$ of the $\mathrm{Ru} / \mathrm{MIL}-53(\mathrm{Al})-\mathrm{NH}_{2}$ catalyst is obviously lower than that of Ru/MIL-53(Al) in this study. From the comparison of the catalytic activities and activation energies of other Ru-based catalysts provided in Table 1, the Ru/MIL53(Al)- $\mathrm{NH}_{2}$ catalyst exhibited a low $E_{\mathrm{a}}$ and an excellent catalytic performance due to the strong bifunctional effects between the $\mathrm{Ru}$ NPs and the MIL-53(Al)-NH $\mathrm{NH}_{2}$ matrix and the uniform

\section{a}

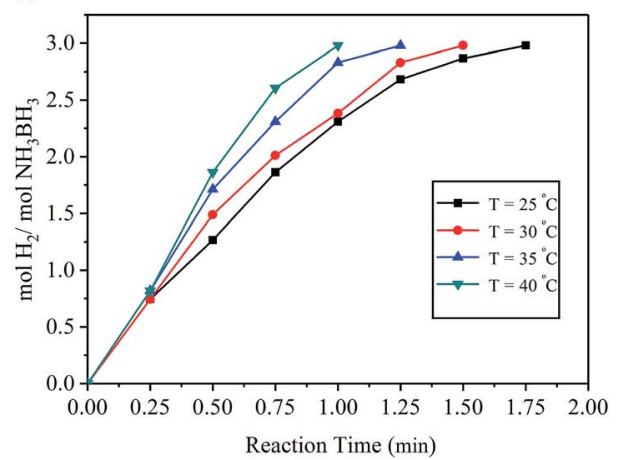

C

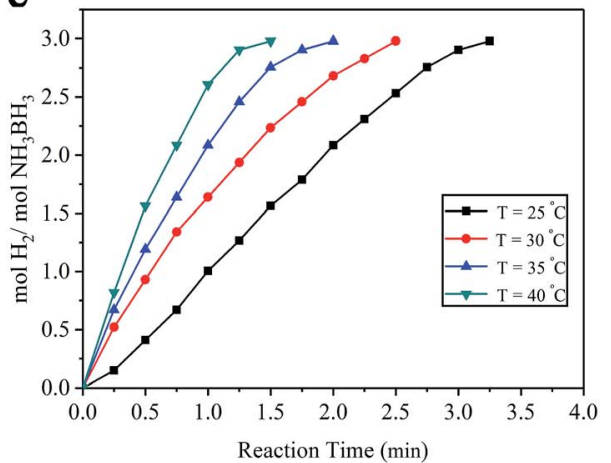

b

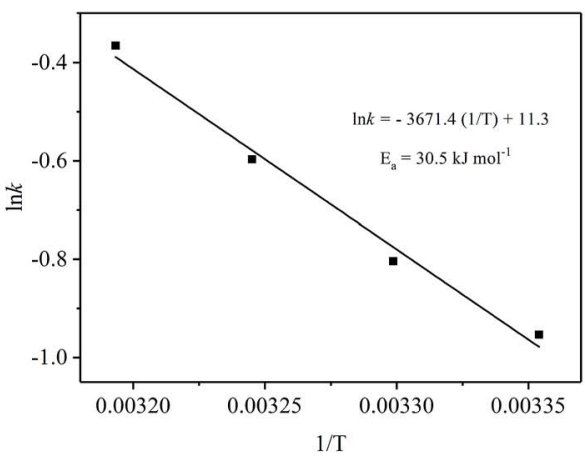

d

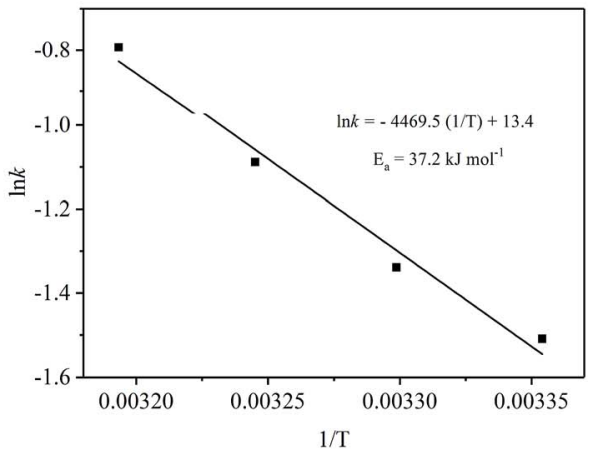

Fig. 6 (a and c) Effect of temperature on the hydrogen generation rate catalyzed by Ru/MIL-53(Al)-NH 2 and Ru/MIL-53(Al) catalysts; (b and d) Arrhenius plots obtained from the corresponding temperature effects. 
distribution of ultra-small $\mathrm{Ru}$ NPs. These results show that the $\mathrm{Ru} / \mathrm{MIL}-53(\mathrm{Al})-\mathrm{NH}_{2}$ catalyst is a good candidate for the dehydrogenation of $\mathrm{AB}$ aqueous solution.

$$
\ln k=\ln A-E_{\mathrm{a}} / R T
$$

In general, the higher the rate constant $(k)$, the higher the TOF. According to the Arrhenius equation (1), the activation energy $\left(E_{\mathrm{a}}\right)$ and the pre-exponential factor $(A)$ have significant influence on the rate constant $(k)$. The activation energy $\left(E_{\mathrm{a}}\right)$ depends on the mechanism of the catalytic reaction, which has a major impact on the rate constant $(k)$ because it determines the slope in the Arrhenius equation (1). In contrast, the preexponential factor $(A)$ depends on the number of active sites and has a minor impact on the rate constant $(k)$ because it determines the intercept in the Arrhenius equation (1). Thus, top priority should be given to reducing the activation energy $\left(E_{\mathrm{a}}\right)$ to obtain high TOF values. Thus, the lower the activation energy $\left(E_{\mathrm{a}}\right)$ is, the higher the TOF value of catalysts, as shown in Table 1. However, in recent years, some studies have shown that when there is little difference between two catalysts' activation energy $\left(E_{\mathrm{a}}\right)$, the difference in the rate constant $(k)$ is entirely due to the variation in the number of active sites, which determine

a

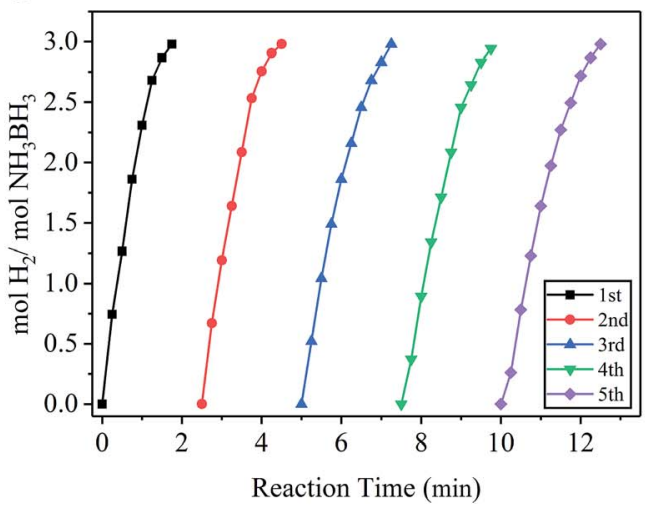

c

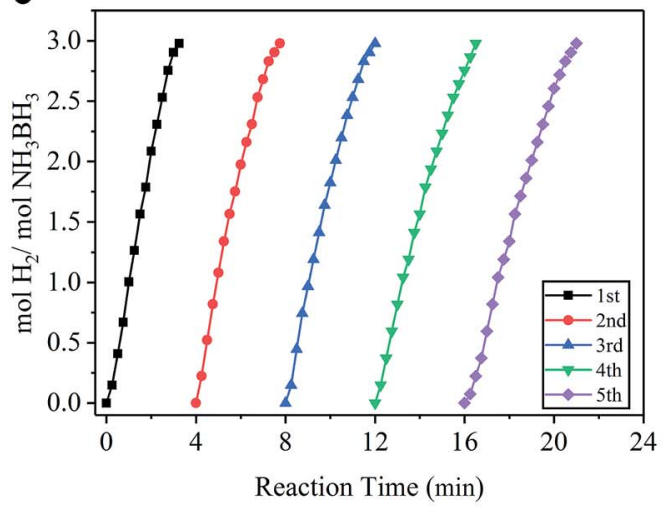

the values of the pre-exponential factor $(A) \cdot{ }^{39}$ In conclusion, the lower the activation energy $\left(E_{\mathrm{a}}\right)$ and the higher the preexponential factor $(A)$, the greater the contribution to TOF values.

Durability studies of a catalyst are essential for its practical application. Thus, the stability of the catalyst in the hydrolytic reaction of $\mathrm{AB}$ was investigated, as shown in Fig. 7a and c. For the durability test, the catalytic reactions were repeated five times by introducing additional equivalents of $\mathrm{AB}(18.5 \mathrm{mg})$ into the mixture after a previous cycle. The definition of loss in catalytic activity is defined as the percentage drop in initial activity based on the slopes of the linear portion of each plot shown in Fig. 7a and c. As shown in Fig. 7b, the Ru/MIL-53(Al)$\mathrm{NH}_{2}$ catalyst retained approximately $87.6 \%$ of its initial catalytic activity in the second cycle of $\mathrm{AB}$ hydrolysis, and $82.1 \%, 79.1 \%$, and $72.4 \%$ of initial activity was retained, respectively, in subsequent cycles. Considering that only $5 \mathrm{mg}$ of catalyst was utilized in the reaction, the performance of this catalyst is impressive. In contrast to the $\mathrm{Ru} / \mathrm{MIL}-53(\mathrm{Al})-\mathrm{NH}_{2}$ catalyst, the $\mathrm{Ru} / \mathrm{MIL}-53(\mathrm{Al})$ catalyst maintained approximately $64.3 \%$ of its initial catalytic activity in the fifth cycle, as shown in Fig. 7 d.

To provide more insight into the reduction in catalytic activity, reusability tests were performed with $\mathrm{Ru} / \mathrm{MIL}-53(\mathrm{Al})$ $\mathrm{NH}_{2}$ and $\mathrm{Ru} / \mathrm{MIL}-53$ catalysts. The definition of loss in catalytic

b

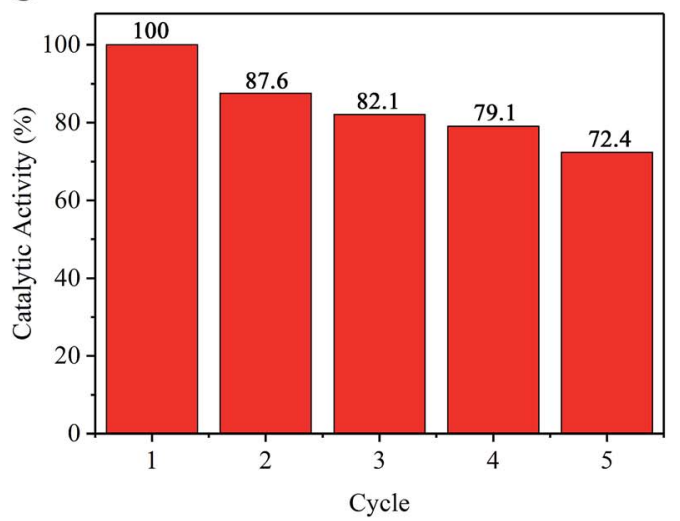

d

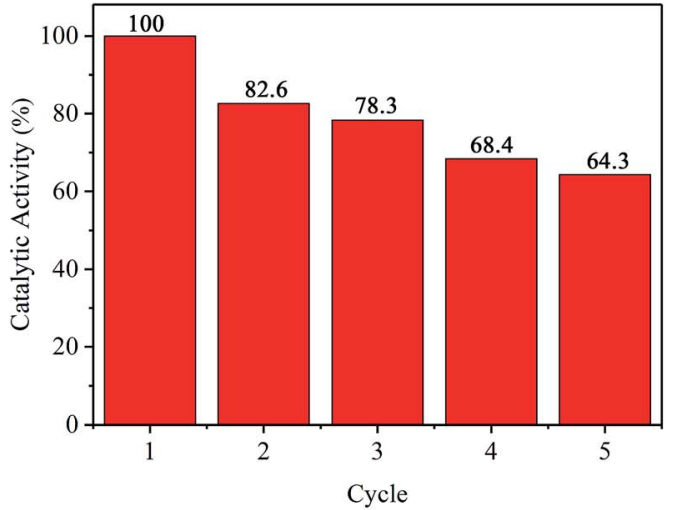

Fig. 7 (a and c) Durability of Ru/MIL-53(Al)- $\mathrm{NH}_{2}$ and Ru/MIL-53(Al) catalysts from the 1st to the 5th cycle; (b and d) corresponding percentage of the initial catalytic activity remaining after successive cycles of $A B$ hydrolysis. 
activity is the same as the durability test. After the completion of each cycle, the solid catalyst was recovered by centrifugation, and the supernatant liquid was decanted. Then, catalysts were washed with deionized water three times and redispersed in deionized water for the next cycle. Fig. $8 \mathrm{~b}$ and $\mathrm{d}$ show the percentages of initial catalytic activity for Ru/MIL-53(Al)- $\mathrm{NH}_{2}$ and $\mathrm{Ru} / \mathrm{MIL}-53$ catalysts in subsequent cycles by using catalysts isolated after each preceding hydrolysis cycle at $25{ }^{\circ} \mathrm{C}$. After the fifth cycle in the reusability tests, $\mathrm{Ru} / \mathrm{MIL}-53(\mathrm{Al})-\mathrm{NH}_{2}$ and $\mathrm{Ru} /$ MIL-53 catalysts retained $86.3 \%$ and $77.5 \%$ of their initial catalytic activity, respectively, for $\mathrm{AB}$ hydrolysis. Therefore, the performance of $\mathrm{Ru} / \mathrm{MIL}-53(\mathrm{Al})-\mathrm{NH}_{2}$ in the reusability test is remarkable. It is obvious that the catalysts have better performance in reusability tests than in durability tests and that $\mathrm{Ru} /$ MIL-53(Al)- $\mathrm{NH}_{2}$ is more durable and reusable than Ru/MIL53(Al). These results reveal that the observed decreases of catalytic activity are mainly attributable to the increasing viscosity of the reaction solution and the deactivation effect caused by the increasing metaborate concentration that many studies have reported. ${ }^{40,41}$ To be more specific, the increasing viscosity of the solution after multiple cycles may impede the diffusion of $\mathrm{AB}$, obstructing the interaction between the Ru NPs and $\mathrm{AB}$, thus resulting in decreased catalytic activity. In addition, the increasing metaborate can be absorbed on the Ru NP surface and cover active sites. Furthermore, as shown in Fig. 3e and f, the Ru particle size increased from 1.22 to $1.60 \mathrm{~nm}$ after the fifth durability test, and the increase of Ru particle size can contribute to the decrease of the catalytic activity reported in many studies. ${ }^{30,42}$ In some reports, metal leaching may have also led to the decline in the catalytic activity.$^{43}$ Generally, metal leaching depends upon the reaction medium $(\mathrm{pH}$, oxidation potential, and chelating properties of the metal) and the bulk and surface properties of the metal. ${ }^{44}$ Moreover, if the $\mathrm{Ru}$ nanoparticles detached from the support, they can easily aggregate in solution, thus resulting in decreased catalytic activity. ${ }^{45}$ In the durability test, the amount of metal Ru that leached from the $\mathrm{Ru} / \mathrm{MIL}-53(\mathrm{Al})-\mathrm{NH}_{2}$ catalyst in the five cycles was determined to be $0.75 \%, 1.05 \%, 1.33 \%, 1.46 \%$, and $1.64 \%$, respectively (see Table 2). Note that this amount of leached metal for the $\mathrm{Ru} / \mathrm{MIL}-53(\mathrm{Al})-\mathrm{NH}_{2}$ catalyst is very low, indicating that the Ru NPs remain effectively embedded in the MIL-53(Al)$\mathrm{NH}_{2}$ host. Additionally, representative TEM images of Ru/MIL53(Al)- $\mathrm{NH}_{2}$ after the fifth durability test also showed that no obvious changes occurred in the morphology or uniform distribution of the Ru NPs (Fig. 3c and d). These results reveal that the amine groups in the MIL-53(Al)- $\mathrm{NH}_{2}$ matrix act as anchoring groups to capture $\mathrm{Ru}(\mathrm{III})$ ions and stabilize ultrasmall $\mathrm{Ru}$ NPs, effectively preventing their aggregation and thus resulting in superior performance in durability and reusability tests.
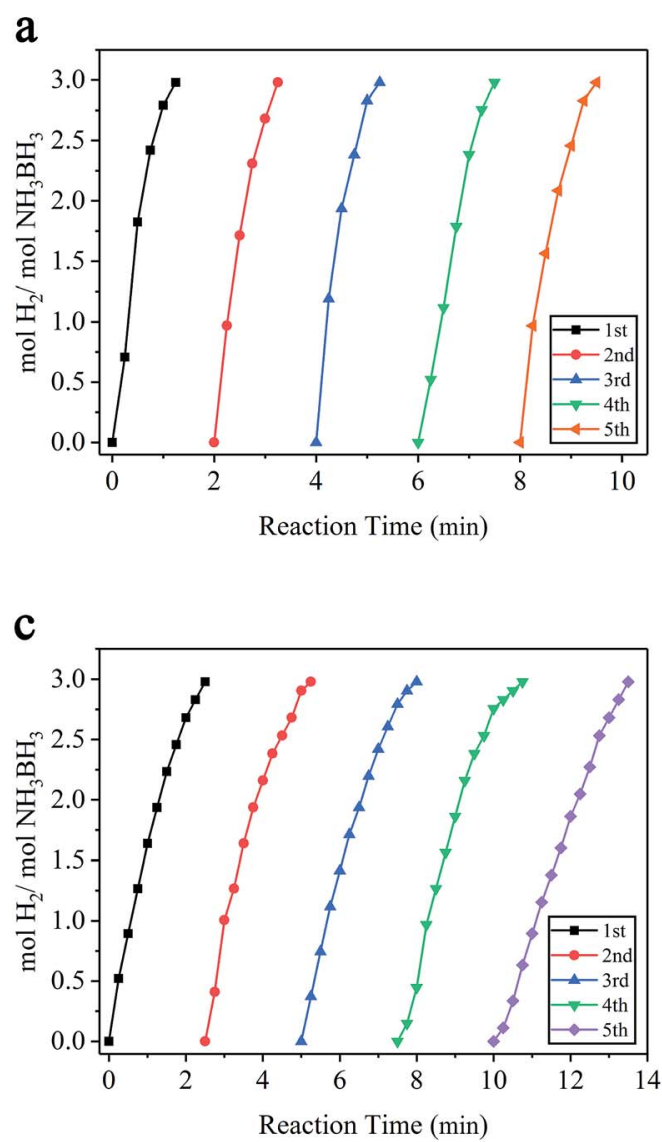

b

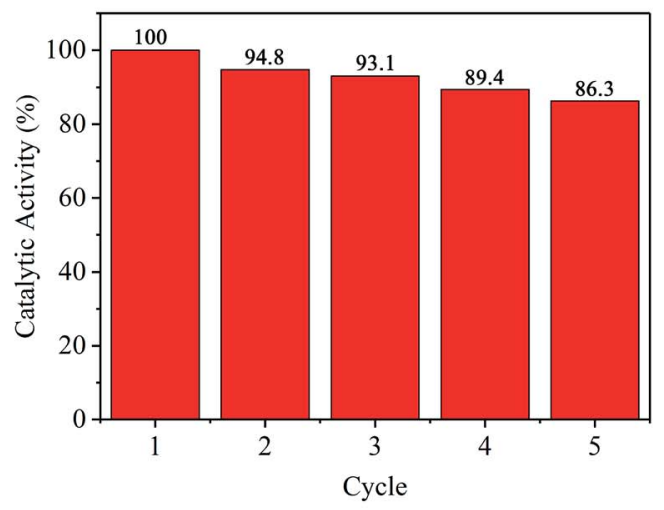

d

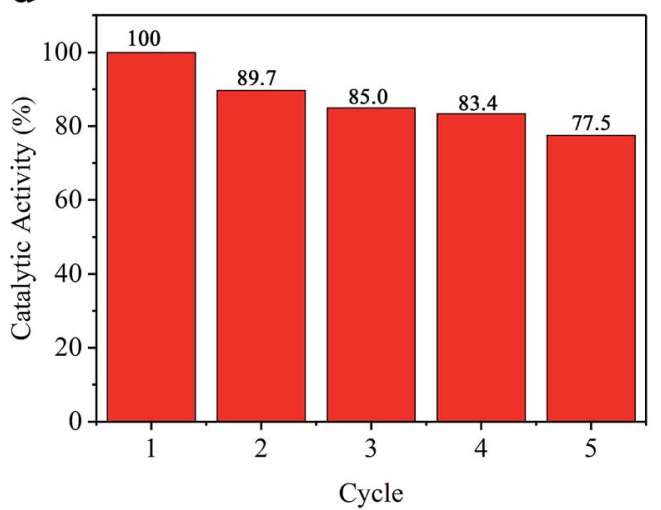

Fig. 8 (a and c) Reusability of the Ru/MIL-53(Al)- $\mathrm{NH}_{2}$ and Ru/MIL-53(Al) catalysts from the 1st to the 5th cycle; (b and d) corresponding percentage of the initial catalytic activity remaining after successive cycles of $A B$ hydrolysis. 
Table 2 Metal leaching of Ru/MIL-53(Al)- $\mathrm{NH}_{2}(5 \mathrm{mg})$ in successive cycles of $A B$ hydrolysis

\begin{tabular}{lll}
\hline Run & Ru leaching $(\mathrm{mg})$ & Metal leaching $(\%)$ \\
\hline 1 & 0.0068 & $0.75 \%$ \\
2 & 0.0095 & $1.05 \%$ \\
3 & 0.0121 & $1.33 \%$ \\
4 & 0.0132 & $1.46 \%$ \\
5 & 0.0149 & $1.64 \%$
\end{tabular}

\section{Conclusions}

In summary, the ultra-small Ru NPs embedded in the MIL-53$\mathrm{NH}_{2}$ matrix exhibited a much higher catalytic activity and lower $E_{\mathrm{a}}$ for hydrogen generation from $\mathrm{AB}$ at ambient temperature compared with Ru NPs embedded in MIL-53. Furthermore, the $\mathrm{Ru} / \mathrm{MIL}-53(\mathrm{Al})-\mathrm{NH}_{2}$ catalyst was recyclable in the hydrolytic reaction of $\mathrm{AB}$, preserving $72.4 \%$ and $86.3 \%$ of its initial activity in the durability test and reusability test after the fifth cycle, respectively. The main property leading to the excellent catalytic performance was the presence of amine groups in the MIL-53$\mathrm{NH}_{2}$ framework, which stabilized the Ru NPs and maintained their ultra-small size and good distribution. Therefore, the $\mathrm{Ru} /$ MIL-53(Al)- $\mathrm{NH}_{2}$ catalyst is a promising candidate for application in the development of $\mathrm{AB}$ as a highly efficient and portable hydrogen storage system. The present work indicates that amine functionalization of the MOF material substantially improved the catalytic performance of the catalyst, and this strategy can easily be extended to other functionalized MOFs and metal NPs.

\section{Conflicts of interest}

There are no conflicts to declare.

\section{Acknowledgements}

This project was sponsored by the Natural Science Fund for Creative Research Groups of Hubei Province (2014CFA015) and the Hubei Province Education Office Key Laboratory (2016-KL007) of China. This work was also sponsored by the Hubei College Students' Innovation Training Program of China (201510 512030).

\section{Notes and references}

1 P. Jena, J. Phys. Chem. Lett., 2011, 2, 206-211.

2 S. Akbayrak, Y. Tonbul and S. Ozkar, Dalton Trans., 2016, 45, 10969-10978.

3 U. Eberle, M. Felderhoff and F. Schuth, Angew. Chem., Int. Ed., 2009, 48, 6608-6630.

4 B. Roy, J. Manna and P. Sharma, J. Alloys Compd., 2015, 645, 234-238.

5 H. Wang, L. Zhou, M. Han, Z. Tao, F. Cheng and J. Chen, J. Alloys Compd., 2015, 651, 382-388.
6 L. Yang, J. Su, X. Meng, W. Luo and G. Cheng, J. Mater. Chem. A, 2013, 1, 10016-10023.

7 L. Wen, J. Su, X. Wu, P. Cai, W. Luo and G. Cheng, Int. J. Hydrogen Energy, 2014, 39, 17129-17135.

8 S. Sorribas, B. Zornoza, P. Serra-Crespo, J. Gascon, F. Kapteijn, C. Téllez and J. Coronas, Microporous Mesoporous Mater., 2016, 225, 116-121.

9 R. Huxford, J. Della Rocca and W. Lin, Curr. Opin. Chem. Biol., 2010, 14, 262.

10 T. T. Dang, Y. Zhu, J. S. Y. Ngiam, S. C. Ghosh, A. Chen and A. M. Seayad, ACS Catal., 2013, 3, 1406.

11 H. R. Moon, D. W. Lim and M. P. Suh, Chem. Soc. Rev., 2013, 42, 1807-1824.

12 T. Gadzikwa, O. K. Farha, K. L. Mulfort, J. T. Hupp and S. T. Nguyen, Chem. Commun., 2009, 3720-3722.

13 S. J. Garibay and S. M. Cohen, Chem. Commun., 2010, 46, 7700-7702.

14 K. Koh, J. E. Seo, J. H. Lee, A. Goswami, C. W. Yoon and T. Asefa, J. Mater. Chem. A, 2014, 2, 20444-20449.

15 M. J. Ingleson, J. Perez Barrio, J.-B. Guilbaud, Y. Z. Khimyak and M. J. Rosseinsky, Chem. Commun., 2008, 2680-2682.

16 R. J. White, R. Luque, V. L. Budarin, J. H. Clark and D. J. Macquarrie, Chem. Soc. Rev., 2009, 38, 481-494.

17 Z. H. Lu, J. P. Li, G. Feng, Q. L. Yao, F. Zhang, R. Y. Zhou, D. J. Tao, X. S. Chen and Z. Q. Yu, Int. J. Hydrogen Energy, 2014, 39, 13389-13395.

18 D. Lu, G. Yu, Y. Li, M. Chen, Y. Pan, L. Zhou, K. Yang, X. Xiong, P. Wu and Q. Xia, J. Alloys Compd., 2017, 694, 662-671.

19 K. Yang, L. Zhou, X. Xiong, M. Ye, L. Li and Q. Xia, Microporous Mesoporous Mater., 2016, 225, 1-8.

20 D. Sun, P. Li, B. Yang, Y. Xu, J. Huang and Q. Li, RSC Adv., 2016, 6, 105940-105947.

21 T. Ahnfeldt, D. Gunzelmann, T. Loiseau, D. Hirsemann, J. Senker, G. Ferey and N. Stock, Inorg. Chem., 2009, 48, 3057-3064.

22 T. Loiseau, C. Serre, C. Huguenard, G. Fink, F. Taulelle, M. Henry, T. Bataille and G. Férey, Chemistry, 2004, 10, 1373.

23 L. Liu, X. Tai, X. Zhou and L. Liu, Chem. Res. Chin. Univ., 2017, 33, 231-238.

24 S. Akbayrak, P. Erdek and S. Ozkar, Appl. Catal., B, 2013, 142, 187-195.

25 M. Rakap, J. Alloys Compd., 2015, 649, 1025-1030.

26 S. Akbayrak and S. Özkar, ACS Appl. Mater. Interfaces, 2012, 4, 6302-6310.

27 K. Yang, L. Zhou, G. Yu, X. Xiong, M. Ye, Y. Li, D. Lu, Y. Pan, M. Chen and L. Zhang, Int. J. Hydrogen Energy, 2016, 41, 6300-6309.

28 C. Nan, J. Su, L. Wei and G. Cheng, Int. J. Hydrogen Energy, 2014, 39, 426-435.

29 X. Xiong, L. Zhou, G. Yu, K. Yang, M. Ye and Q. Xia, Int. J. Hydrogen Energy, 2015, 40, 15521-15528.

30 G. Fan, Q. Liu, D. Tang, X. Li, J. Bi and D. Gao, Int. J. Hydrogen Energy, 2016, 41, 1542-1549.

31 Q. L. Yao, W. M. Shi, G. Feng, Z. H. Lu, X. L. Zhang, D. J. Tao, D. J. Kong and X. S. Chen, J. Power Sources, 2014, 257, 293299. 
32 S. Akbayrak, M. Kaya, M. Volkan and S. Özkar, J. Mol. Catal. A: Chem., 2014, 394, 253-261.

33 E. B. Kalkan, S. Akbayrak and S. Özkar, J. Mol. Catal. A: Chem., 2017, 430, 29-35.

34 S. Akbayrak and S. Ozkar, Dalton Trans., 2014, 43, 1797-1805. 35 P. Pachfule, X. Yang, Q.-L. Zhu, N. Tsumori, T. Uchida and Q. Xu, J. Mater. Chem. A, 2017, 5, 4835-4841.

36 H. Can and O. Metin, Appl. Catal., B, 2012, 125, 304-310.

37 D. D. Ke, Y. Li, J. Wang, L. Zhang, J. D. Wang, X. Zhao, S. Q. Yang and S. M. Han, Int. J. Hydrogen Energy, 2016, 41, 2564-2574.

38 Q. Xu and M. Chandra, J. Power Sources, 2006, 163, 364-370.
39 X. W. Xie, Y. Li, Z. Q. Liu, M. Haruta and W. J. Shen, Nature, 2009, 458, 746-749.

40 M. Rakap and S. Ozkar, Int. J. Hydrogen Energy, 2010, 35, 3341-3346.

41 Ö. Metin, Ş. Şahin and S. Özkar, Int. J. Hydrogen Energy, 2009, 34, 6304-6313.

42 N. Cao, W. Luo and G. Z. Cheng, Int. J. Hydrogen Energy, 2013, 38, 11964-11972.

43 D. D. Gao, Y. H. Zhang, L. Q. Zhou and K. Z. Yang, Appl. Surf. Sci., 2018, 427, 114-122.

44 M. Besson and P. Gallezot, Catal. Today, 2003, 81, 547-559.

45 H. Liang, G. Chen, S. Desinan, R. Rosei, F. Rosei and D. Ma, Int. J. Hydrogen Energy, 2012, 37, 17921-17927. 